\title{
CRISPR System: From Adaptive Immunity to Genome Editing*
}

\author{
Jennifer Doudna ${ }^{1}$
}

CRISPR-Cas9 is a revolutionary genome-editing tool. Understanding how Cas9 recognizes DNA and how to control its function will be critical in improving the system. We used single-molecule FRET to elucidate a key validation step during DNA target recognition. We also used X-ray crystallography to show how a Cas9 inhibitor is able to permit DNA binding but prevent cleavage. Finally, CRISPR research is notable not just for the exciting applications, but also for its profound ethical implications.

Keywords: CRISPR; Genome Editing; Biochemistry; Structural Biology; Bioethics.

So, what we're going to hear about in the next two talks is research that I think has a lot of themes that we heard about this morning, a fundamental discovery, curiosity-driven research, scientists who were working collaboratively internationally together on a project that was aimed at answering a particular question, as l'll tell you, but ended up in a very different direction from where we expected it to go in the beginning. And, you know, I think those are the themes that I really have always valued myself as a scientist. And especially, for the students that are in the audience, I wanted to tell you a little bit about my own background, how I came to do what I'm doing and how fortunate to have the opportunity to do science.

So, you know, I think the story really begins with thinking about how information is encoded biologically. You know that we're all kind of comfortable now with computers and how information is encoded electronically, but in cells, of course, information is encoded chemically and its encoded in DNA. Scientists have understood for decades that this molecule, the double helix is really about giving the instructions to the cells or organisms that allow them to divide, to develop into certain types of tissues or whole organisms. And that by understanding what that information is and how to manipulate it, we can have a lot of ability to control biological systems, and we already heard a lot about that in Francis Arnold's talk.

And for me, when I was growing up, I grew up in a small rural town in Hawaii. Nobody in my family was a scientist, but my dad was a professor of American literature and he loved shopping in used bookstores. And so, one day I came home from school, I was probably in sixth grade and he had left a copy of The Double Helix on my bed, sort of a bent, dog-eared paperback copy of Jim Watson's famous book. And it.. just...I picked this book up and I had no idea what it was about. And I read it and it kind of blew my mind because it was really about the story of how scientists had figured out the structure of the double helix, how they had done experiments to actually understand the structure of a molecule as important as this. And I think for me when I think back on it, that was kind of the moment when I really thought to myself, wow I wonder if I could do something like that someday, not something that momentous of course but just how could I have the opportunity to do science, could I do research, could I, you know, solve puzzles in biology or chemistry by asking questions and then answering them experimentally. It seemed like a really exciting possibility. So, as I went along in my career, I went to college, I majored in chemistry with a focus on biochemistry. And then I had the good fortune to go to graduate school and join the laboratory

\footnotetext{
${ }^{1}$ Howard Hughes Medical Institute, University of California, Berkeley, CA 94720-3220, USA. Published online 26 September 2017; doi:10.1142/ S2529732517400090

* This article was transcribed from a presentation delivered by Professor Doudna at the Molecular Frontiers Symposium on Tailored Biology at the Royal Swedish Academy of Sciences, May 2017. It is published here in MFJ with permission from Professor Doudna. This is an Open Access article published by World Scientific Publishing Company. It is distributed under the terms of the Creative Commons Attribution 4.0 (CC-BY) License. Further distribution of this work is permitted, provided the original work is properly cited.
} 


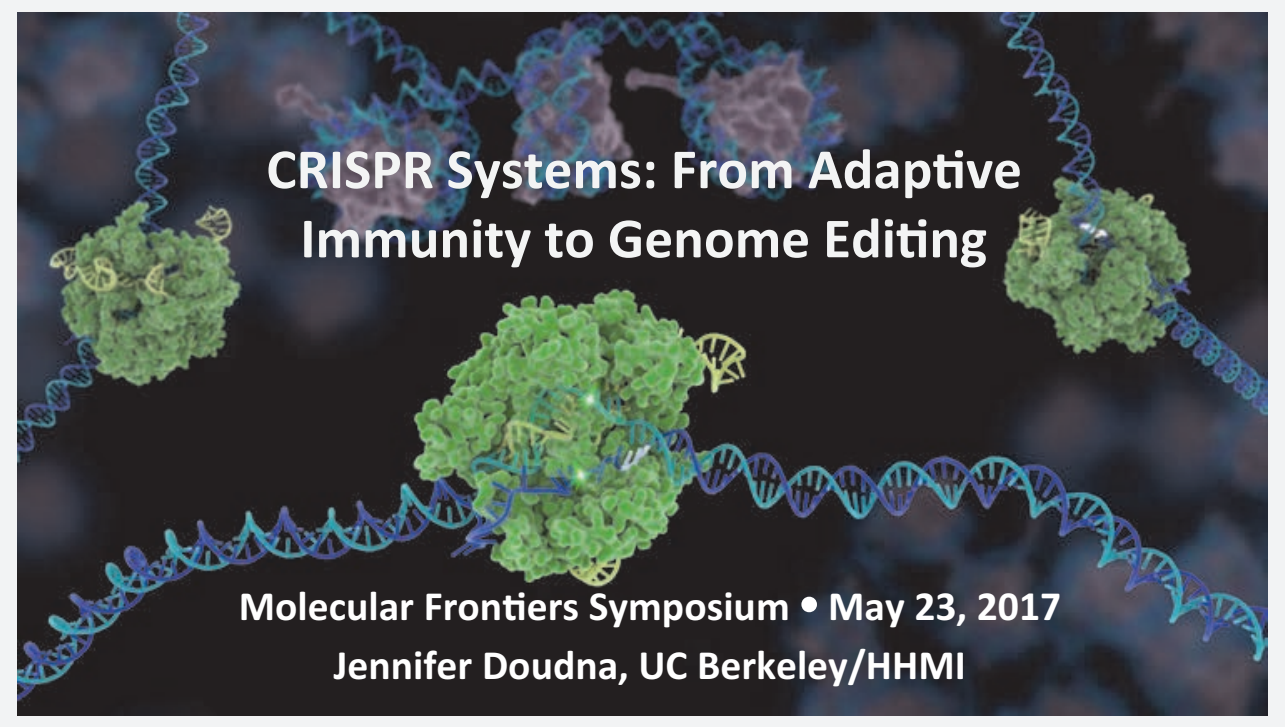

biology and understand where it came from. And so, this is really just showing a very simplified view of the central dogma, but fundamentally information is encoded in DNA. It gets transcribed into molecules of RNA, which are sort of I call it DNA's chemical cousin, as it has the same sort of

of Jack Szostak. When I got to Jack's lab, there was a lot of work that had gone on in his lab in the past about genetic recombination and the way that the ends of chromosomes called telomeres are structured and how they're replicated. But, that was kind of in the past for him and he was really moving in a different direction. He was thinking about the origin of life, a lot of the questions that he talked about this morning. And so, when I joined his lab, I had chemistry background, I didn't know too much about biology really, but we thought a lot about sort of this what we call the central dogma, how information is encoded and how it's passed along from generation to generation biologically and how that feeds evolution and then if we look back in time, can we look at what's happening in modern

\section{A cell's DNA holds the key to its growth and development}

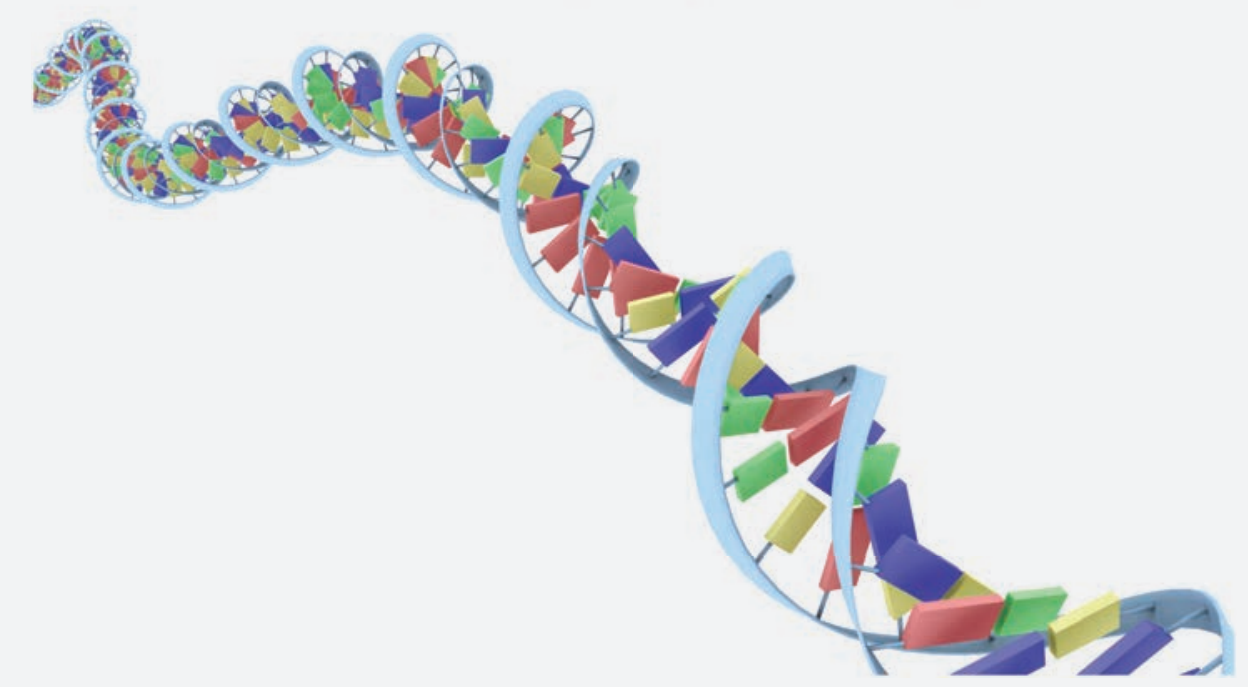

polymeric structure of four individual letters that make up RNA molecules. And then, if these RNA molecules are messenger RNAs, they actually encode proteins that the cell will then recognize as a coded message that tells the cell how to make a certain type of protein. And so, all of these proteins then get made and they carry out most of the functions in the cell. But, when I was starting graduate school, one of the things that was really, really exciting and kind of mind blowing at the time was that scientists, including Altman and Chuck and Norman Pace and a few others had figured out that there are examples in biology of RNA molecules that have function in their own right. They're chemically active, they can function as catalysts. And this was something that had caught Jack's attention, in particular, because of thinking about the origin of life and could these kinds of cataIytic RNAs that we call ribozymes could they actually tell us something about early evolution. So that was a project that I started working on as a student.

And so, really, when I...over the course of my career, I've continued with that sort of central theme of really thinking about the function of RNA molecules in 


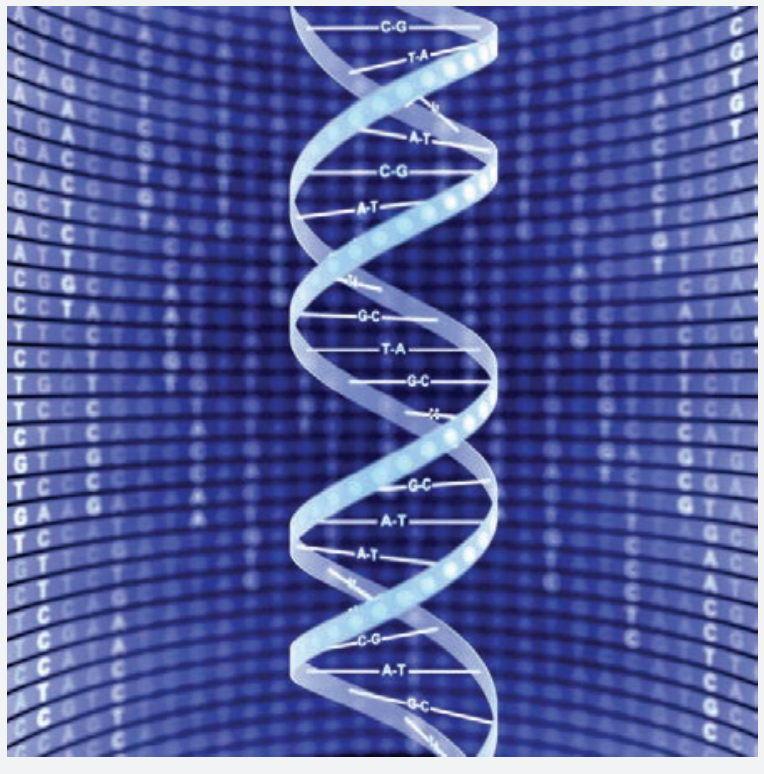

biology and in particular, RNA molecules that don't encode proteins, but actually where the buck stops here. In other words, this molecule has a function in its own right that is important for biological systems. And...early in my career when I went on to do my postdoc in Boulder, Colorado, in the lab of Tom Cech and then later when I started my own lab at Yale University, the first few years of my work were focused on figuring out the molecular structures of these kinds of RNAs that are functional as RNA, you know, functional as catalytic RNAs in particular. And it was really through that line of research that I eventually started thinking about how to link that more chemically and structurally focused line of research to what happens in modern biology. And in particular, all of the work that was going on around me at the time where many

\section{The "central dogma"}

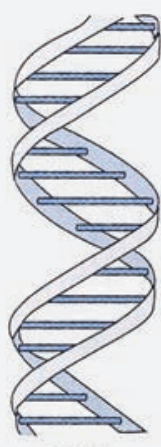

DNA

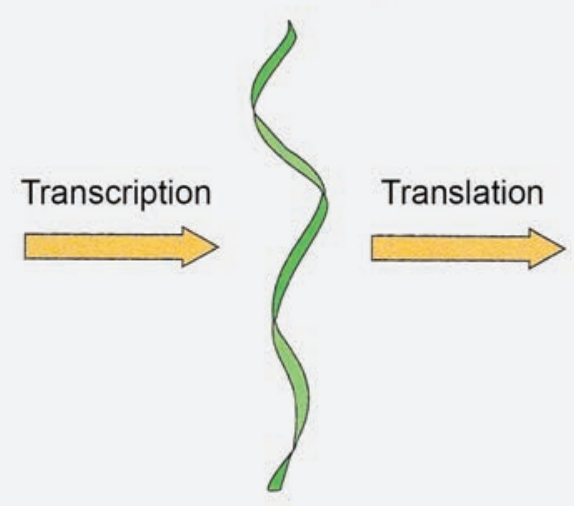

mRNA people were discovering more and more examples of RNA molecules that do very interesting things to control the way that information is expressed in cells. In other words, how DNA, the information encoded in DNA is actually deployed in the cell. Turns out that RNAs... in many...there are many really interesting examples now where RNA molecules are really the mediator of that kind of deployment of information.

And in particular, we started working on small RNAs called microRNAs that are made in many types of animal and plant cells, cells that we call eukaryotic cells that are used to control the flow of information and working on the molecular mechanisms by which those microRNAs are produced in cells and how they are actually able to interact with molecules, other RNA molecules in cells and control the way that proteins are made.

And why am I telling you all of that? Well, that's really the precursor to the story of CRISPR, for me at least, because it was through that early work in my lab, once I moved my lab to UC Berkeley in 2002 that I got acquainted with a colleague there Jill Banfield who was working in a completely different college in a different field. She is not an experimental biologist, she does only computational work. But, her lab was working away on bacteria that are found in various interesting environments. And she would go on these crazy trips to Australia and the outback of California even and isolate samples of bacteria that were growing in pools that were very acidic, $\mathrm{pH} 1$ and or very low or high temperatures and try to figure out what kinds of bugs were growing there. And the way they did that was simply to sequence all of the DNA in those samples and then piece back together the bacterial chromosomes, which are illustrated by this circular drawing here. And then from that sequencing information, figure out what kinds of bugs were growing in those environments. And importantly also, the kinds of bacteriophage, the kinds of viruses that would infect those cells because it turns out that just like us and virtually every other form of life that we know on this planet at least, there are viruses that can infect cells and take over their machinery for making new viruses.

So, Jill Banfield was doing this research and I didn't know anything about it. And then one day, she called me because she said, you know, we've come across something very interesting in our work and it's very puzzling. And I think as an RNA biochemist, you might be someone who can help us. 
And I thought, really? And, so we got together and what she told me was that her lab and really just a couple of other labs around the world at that time were uncovering more

\section{Sometimes RNA functions without} encoding proteins

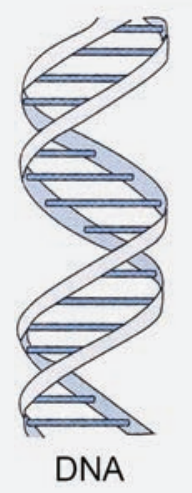

\section{Transcription}
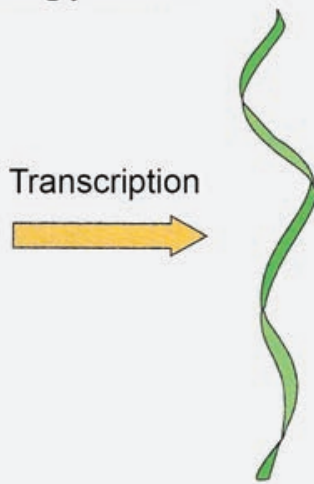

RNA and more examples of sequences that had become known as CRISPRs which stands for clusters of regularly interspaced short palindromic repeats. A big mouthful, you can see why we call it CRISPR. It's an easy acronym. And what is a CRISPR? Well, it really refers to a pattern of DNA sequences that are found naturally in many bacterial genomes and other kinds of single-celled organisms as well that include a series of DNA sequences that are repeated again and again, these black diamonds. They often have partial palindromic characters so they can be read in the forward and reverse direction in the same way. So they have the possibility, if you look at the letters of DNA, they have the possibility of base pairing to form a cruciform sort of structure. And really importantly, in between the repeats in these loci in the genomes that Jill was studying were sequences that were unique and were found in these three papers published in 2005 from three different bioinformatics teams to correspond in many cases to sequences found in viruses. And not only that, they were found in viruses that infect these organisms. And that's what Jill's research had shown a connection to. And her work also shows that these sequences evolve over time. So if you isolate bacteria from a certain site, somewhere in some acid mine tailing or something like that, and then you sequence it and then you go back two weeks later, isolate the sample again and sequence it again, you can find in many cases that now these CRISPR loci have changed and they've changed in a very particular way where new inserted sequences, new examples of these colored boxes have been integrated into the CRISPR locus. So it really looked like this was some kind of evolving system. And the fact that these integrated sequences targeted viruses hinted that this might be some kind of adaptive immune system, a way that bugs could acquire immunity to bacteriophage by storing

\section{CRISPRs: Biology and Technology}

- CRISPRs: RNA-guided genome protection

- Anti-CRISPRs: Phage fight back!

- Ethics: Responsible progress

\section{CRISPRs: Biology and Technology}

- CRISPRs: RNA-guided genome protection

- Anti-CRISPRs: Phage fight back!

- Ethics: Responsible progress 
Adaptation

Expression

Interference

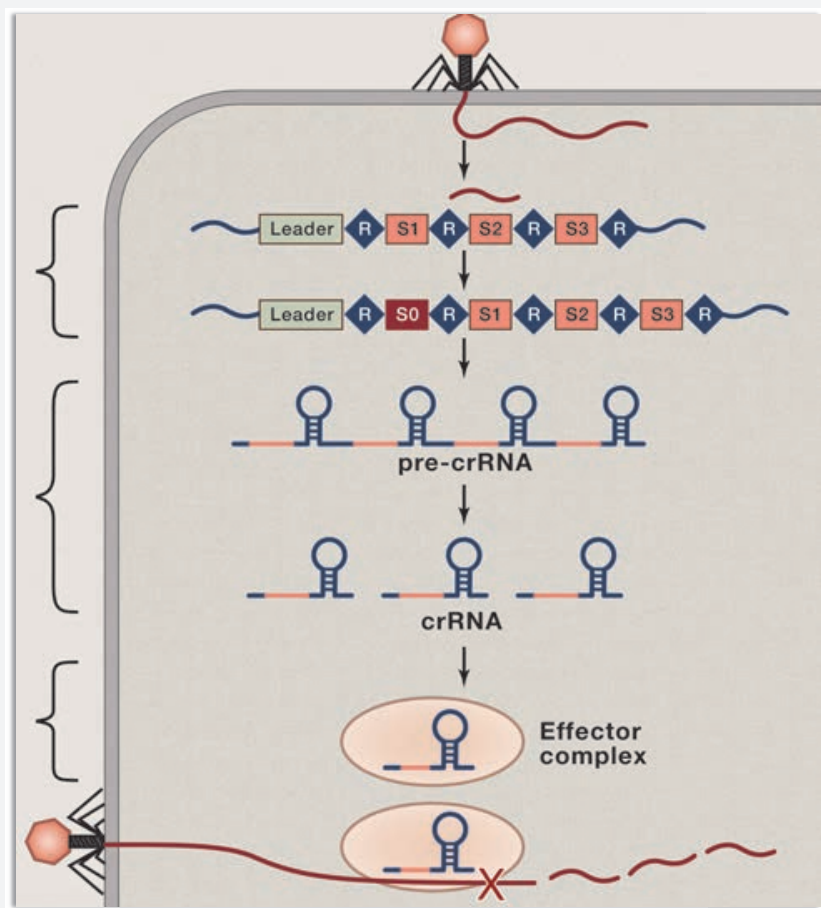

Adaptation

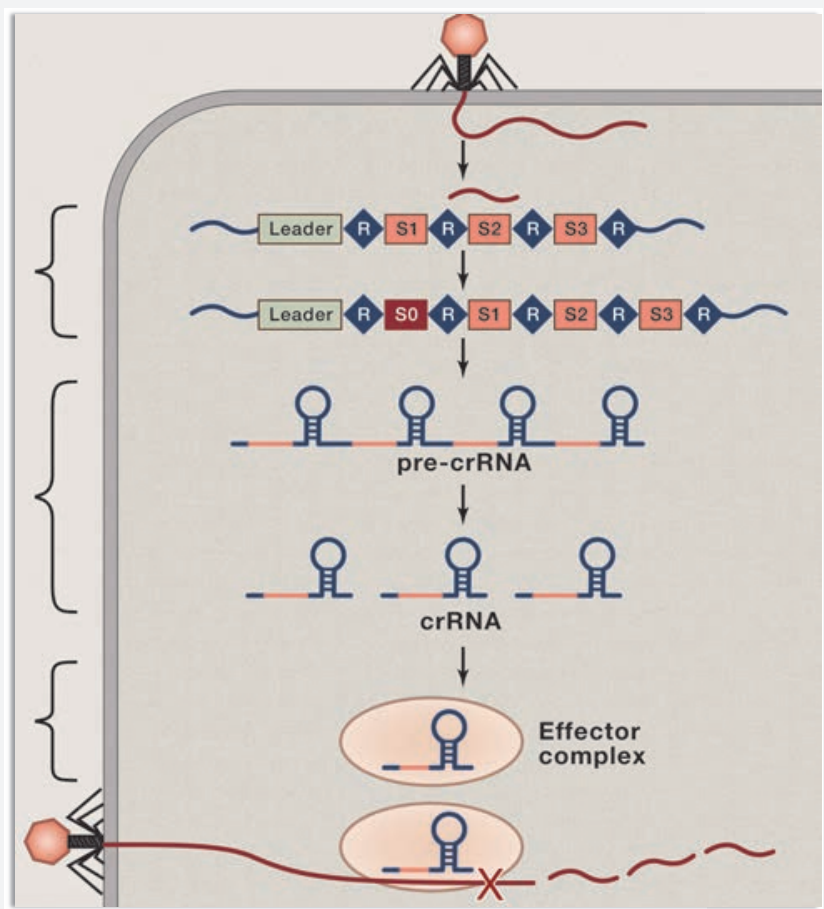

it might be some kind of a system that was being maintained in bacteria was the fact that next door in the genome of bugs that have these CRISPR loci were typically CRISPR associated or cas genes, genes that seem to be co-varying with the presence of CRISPR loci.

So, it seemed very interesting, but what did this have to do with RNA? And Jill's idea at the time and Eugene Koonin had also proposed this, was that maybe these sequences were actually being deployed in cells in the form of small RNA molecules. Something that might be very analogous to the RNA interference pathways found in eukaryotic cells. And that at that point we hadn't found examples of those in bacteria. So she wondered if there might actually be a role for RNA molecules transcribed from these loci and finding and perhaps destroying or somehow protecting cells from future infection by viruses that contained matching sequences. It was sort of a really fascinating idea. So I was hooked. It would seem like a really interesting problem for my lab to engage with.

So, what I'm going to talk about in the rest of the talk today is really three things. I want to tell you a bit about the molecular mechanism of RNA-guided genome protection, which is exactly what CRISPRs really are. And I'm going to let, Emmanuelle will obviously tell you a lot more about the microbiology around this and how her lab got involved in studying these, from again a very different angle, but one that led us eventually to meet each other and start working together.

I'm going to tell you a little bit about something we've been working on recently with a few col-

a little piece of genetic information from each virus that infected the cell in this particular place, this very special place in the chromosome. And then what made this look also like laborators. Molecules called anti-CRISPRs which is how phage actually fight back against CRISPR systems and what we're learning about how these actually work. And then at the end I'm 


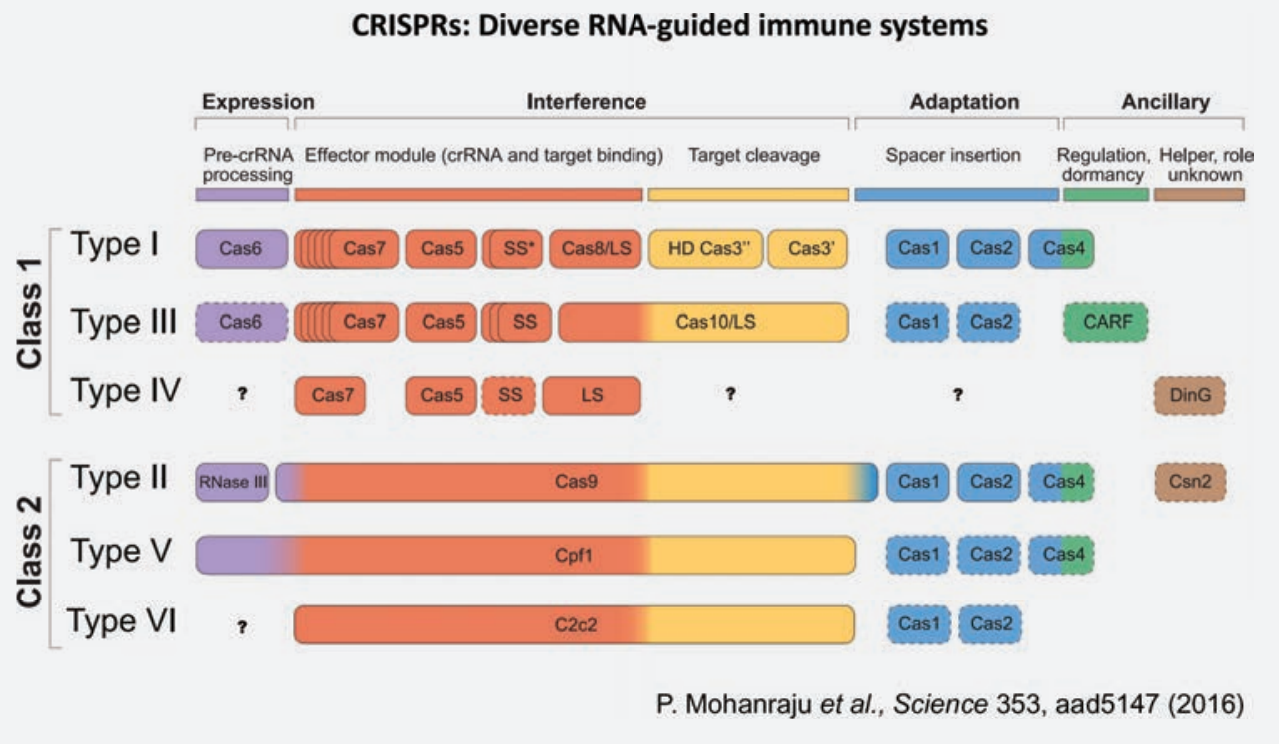

What is the function of CRISPR-Cas9?

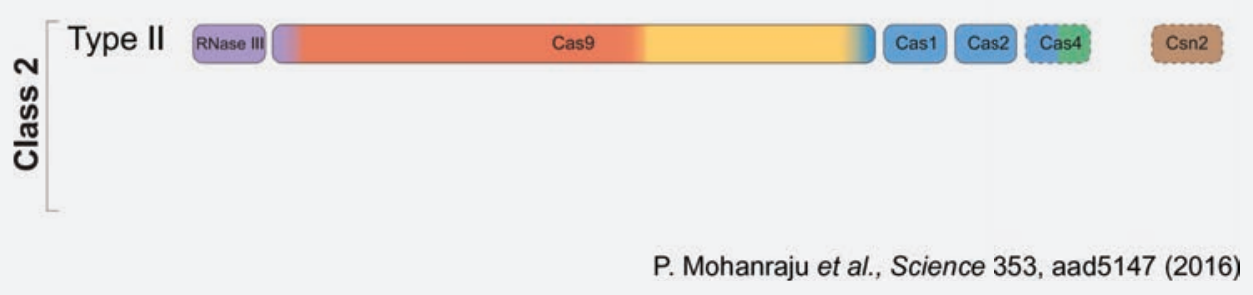

with my collaborators and how we could work together as scientists to encourage what I call responsible progress. So, but first, let's talk about CRISPRs.

So, this is a cartoon that illustrates sort of what we understand currently about the pathway of these adaptive immune systems. And we can kind of break these down into three stages of immunity. So, the first step is that a cell, here's the membrane of a cell, gets infected by a virus. And you can see this phage has landed on the surface of the cell, it's injecting its DNA into the cell. And then if this lucky cell has a CRISPR system that's active, it can actually acquire small bits of this foreign DNA and integrate it into the CRISPR locus here in a process that we call adaptation. So this now newly inserted sequence provides a genetic record of infection by this virus. And then, how is it used to protect the cell? Well, the cell can actually transcribe across this locus to make an RNA molecule. This initially is in many systems is made as initially as a precursor CRISPR RNA, which I'm abbreviating pre here. So this is the precursor RNA molecule. Note that in the palindromic parts of the repeats, these RNA molecules can actually fold back to form little hairpins and we know that's actually important for how they're recognized sort of tags the RNA in the cell and tells the cell this is a CRISPR RNA. And then those RNAs are chopped apart and used to generate individual molecules that each includes a sequence derived from a virus. And those RNAs then assemble with one or more of the proteins encoded by the cas genes to form effector complexes. These are the surveillance complexes that can go going to talk about something that I never imagined in my beginning of my career as an RNA biochemist and structural biologist that I would get involved in, which is thinking about the ethics of technology that came out of work that had been done in my lab 


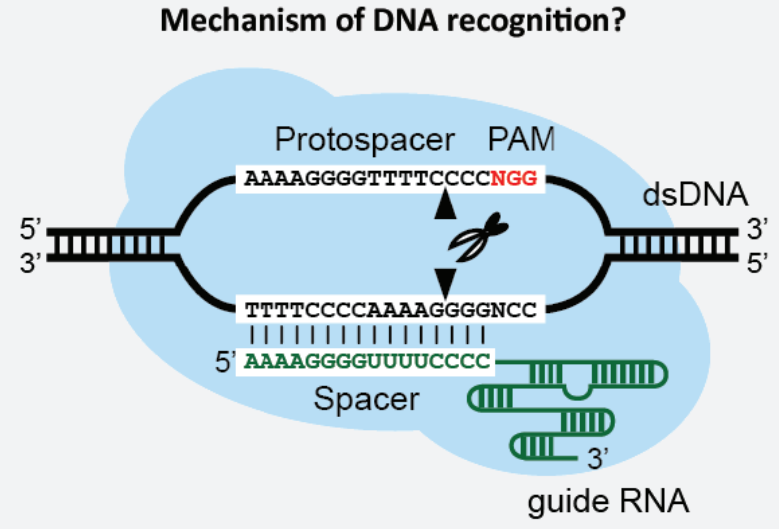

searching through the cell looking for a sequence of nucleic acid that matches the sequence in the CRISPR RNA. This piece right here. And when that occurs then that effector complex is recruited to the nucleic acid through base pairing and allows the associated cas proteins to cleave the viral DNA. So it's a really, really interesting way that bacteria have evolved to adapt to viruses and fight back.

So, in my lab over the last, gosh almost little over 10 years now, we've been working on these systems and we've really been studying all aspects of this, the adaptation step, the expression and processing of RNA and then the way that interference works here, but today, l'm just going to really focus on this step here, which is interference and how these systems are able to protect cells and how an understanding of the mechanism of that led to recognition that this could be harnessed for a very different purpose, namely for genome editing.

So, one of the things that's really cool about CRISPR systems, and I think Emmanuelle might say what about this is that they're really diverse. And this is actually a slide that's taken from a review that was published last year. And what this is showing you in cartoon form is a diagram of the number of genes, number of cas genes that are part of different CRISPR systems that are organized here. And we can very roughly divide these into class I in the top and class II. And the way they differ from each other is that the class I systems all include multiple cas proteins that we know have to come together with the CRISPR RNA to form these targeting complexes.
So there we've done a lot of work on these in my lab over the last few years and others have too and we know that these are now big assemblies, they're very beautiful if you look at the structures and they work by using the information in the CRISPR RNA to find and ultimately to cut foreign nucleic acid. But down here these systems that are called class II are set up differently in the sense that in each case these class II systems have a single cas gene that is responsible for RNA-guided genome protection. And so, initially, we were at my lab, we're sort of focused on, actually working mostly on the type I systems up here in the early days of CRISPR in my lab. And then in 2011 I went to a conference at the American Society of Microbiology and I met Emmanuelle. And she was working on an organism called Streptococcus pyogenes. And in her research on the pathogenesis of this organism, she had been studying all of the small RNAs that are made in this bug and that had led, and I won't spill here sorry, but that had led to some very interesting discoveries about how the CRISPR RNA and another RNA called Tracr are produced in those cells and had led to a very nice publication that she had put out earlier that year.

So, when we met at the conference we decided to team up to work on a very, what seemed at the time like a really just fun, interesting question, which was what is the function of this protein called Cas9. At the time it was actually called Csn1. So it's had a name changed since then. But this protein was part of the CRISPR system found in Streptococcus pyogenes and it's a great example of systems that are known as type II that have a single gene called Cas9, that is

\section{Catalytic domain rotation activates Cas9}

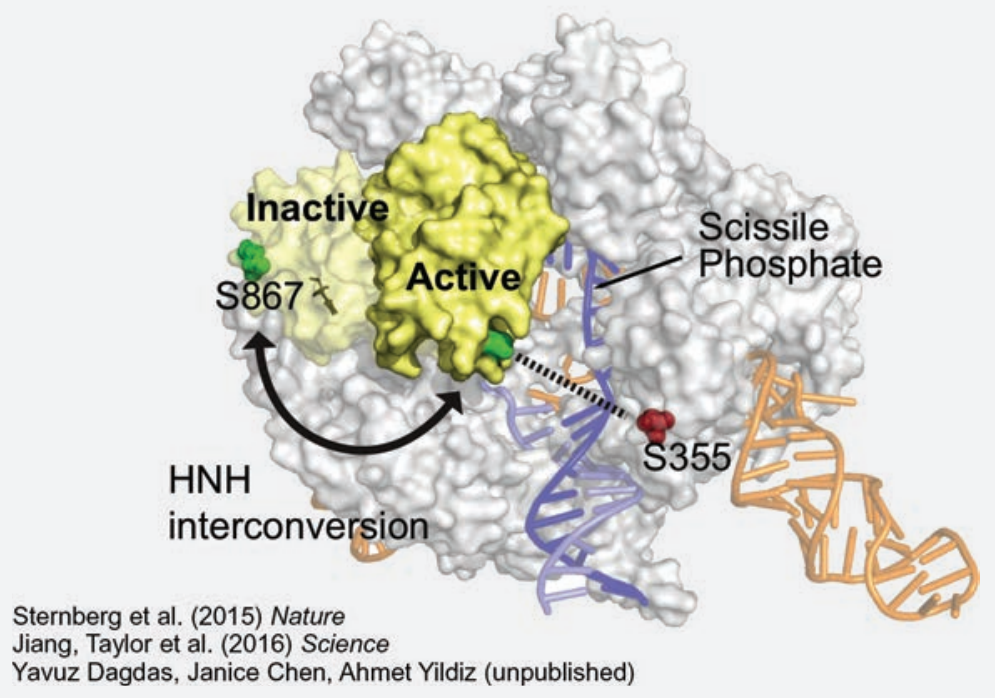




\section{Single-molecule FRET detects Cas9 conformational states}
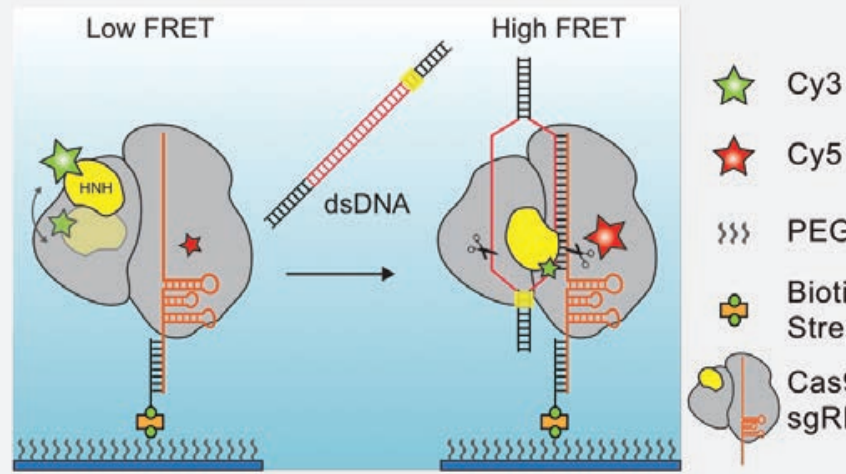

Biotin/ Streptavidin

Cas9sgRNA

Yavuz Dagdas, Janice Chen, Ahmet Yildiz

responsible for protecting cells from viral infection in bugs that have this type of CRISPR system. And at the time, there was genetic evidence that this gene was somehow responsible for that protection, but nobody knew the molecular function of the protein that it encoded. And that was the question that we set out to address. And that led to a really, really fun collaboration that was going on across thousands of miles. Her student, Christoph Zielinski was in Vienna, Emmanuelle herself was here in Sweden at Umea University and my lab in Berkeley, California had Martin Jinek, former post-doc who was working on the project from our side. And so Christoph and Martin teamed up to do a series of biochemical experiments that led to the realization that Cas9 is an RNA-guided DNA cutter. And so what I'm showing you in this cartoon is an illustration, a very low

\section{Cas9 detects RNA-DNA hybridization}

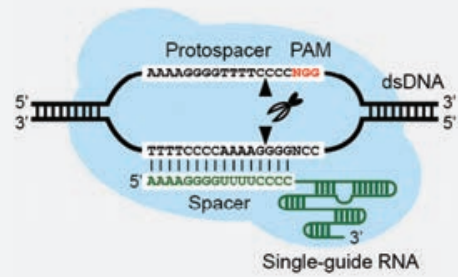

Yavuz Dagdas, Janice Chen, Ahmet Yildiz resolution illustration of Cas9, this blue molecule, that is the protein that protects cells using this RNA-guided mechanism. And we found out that the way it works is it uses an RNA molecule. In nature it's actually two separate RNAs, a CRISPR RNA (crRNA) that contains the targeting sequence which in bacteria would come from a virus, and then a separate RNA called tracrRNA that base pairs with the end of the CRISPR molecule to form a structure that is recognized by Cas 9 . And so this dual RNA interaction binds to Cas9 protein to form the functional complex that can interact with DNA molecules. And when that interaction occurs through base pairing between the RNA and one strand of the DNA, the protein is able to unwind the DNA inside the protein and trigger a double stranded DNA break using two separate active sites in the enzyme that cut each strand of the DNA. And Martin Jinek was able to figure out. He made mutations in the active sites of the enzyme and figured out which one cuts which strand of the DNA. And furthermore, that you could actually make mutations in those active sites and maintain the ability of Cas9 to have this RNAguided DNA binding ability, but with mutated active sites, it would not cut the DNA and we thought that could be something that seemed like a really interesting feature that the chemistry of DNA cutting was entirely separate from the RNAguided activity of the protein. We also figured out that there's a little motif in the DNA next to the site that's targeted called the PAM which for this enzyme is a GG dinucleotide. And this was all figured out by using a reconstituted system where we had purified protein, purified RNA. And that led to the realization that we could actually simplify the system compared to what nature has done by linking together the CRISPR RNA and the tracrRNA to create a single guide form of the RNA that would work for this kind of DNA recognition and cutting. And I think for us it was really when 


\section{A conformational checkpoint for Cas9}

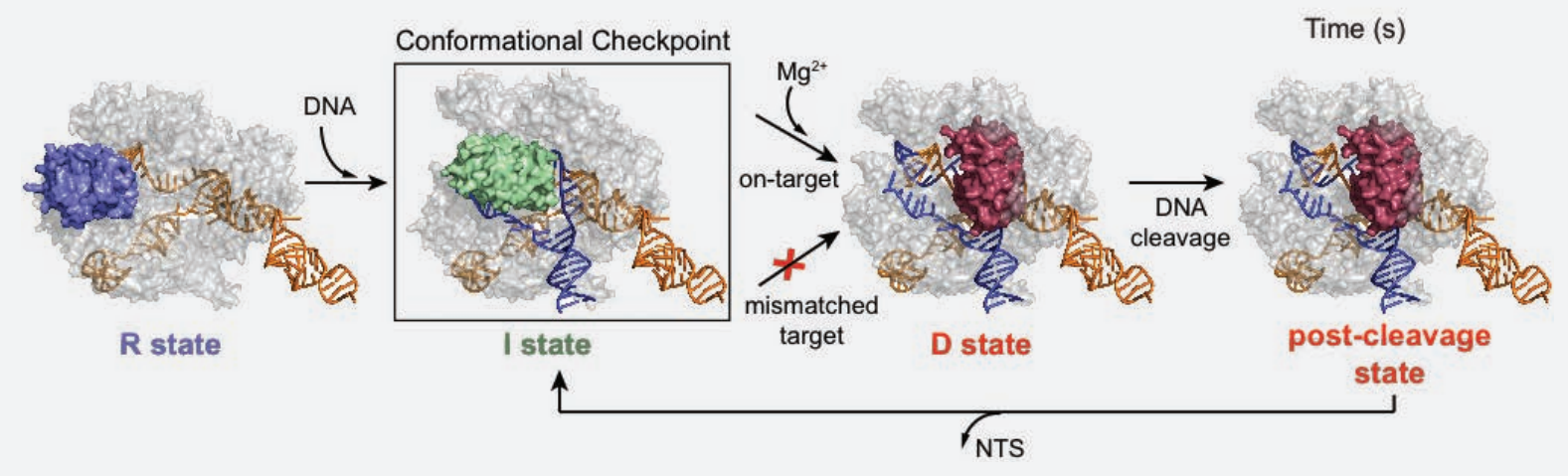

we had that, that result and showed that we could get this to work as a two component system with a single Guide RNA (sgRNA), that we realized that there was a very interesting and very different application of this that could be really exciting from a technology perspective.

So, let me show you a little video. It was also made by Janet Awasa, the person who also made the video that Jack showed this morning, that illustrates how these systems work. So let's see.

So here we have some bacteria that are being invaded by a bunch of viruses. And when a virus infects the cell, of course, here it is injecting its DNA, here is the chromosome. And if this all has a CRISPR locus, it's able to acquire a new piece of the foreign DNA into the CRISPR sequence by integrating it directly into this array. And as I showed you in the cartoon before, this array is then copied into a molecule of RNA that gets chopped into individual units that each includes

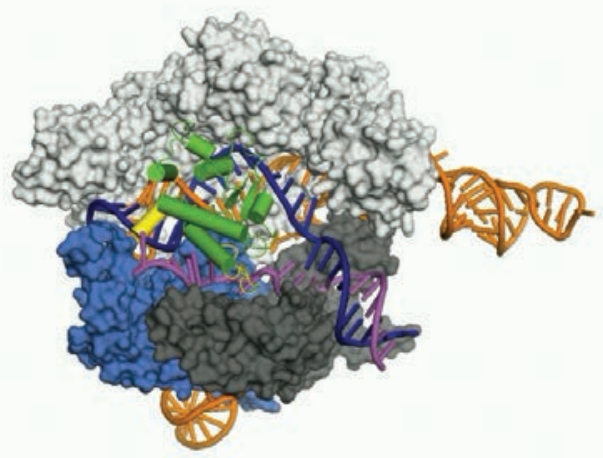

Jiang \& Taylor et al. (2016) Science one of the virally derived sequences. Those molecules combine with the tracrRNA this separate molecule that interacts at the end of the CRISPR molecule to form a binding site for Cas9. And then together, this RNA protein complex goes out searching around the cell to find examples of nucleic acids that match the sequence in the CRISPR RNA. And if a match is found, then this protein RNA complex can assemble with the DNA, unwind it, and allow an RNA-DNA hybrid to form inside. It actually happens inside the protein. And then there's cutting of the two strands of the DNA that in bacteria leads to degradation of the viral DNA. So, great way to destroy viral DNA, but it turns out from research in many labs over the years including in Jack's, that when animal or plant cells, eukaryotic cells experience a double-stranded break to their DNA, they can repair the break by introducing changes at the site of the break. And so, people had appreciated that if you could introduce double-stranded breaks into genomic DNA at a particular place, that would trigger this kind of repair and you could use this for very precise genome engineering and there was a whole line of research that had led to the development of programmable proteins to do this. And those technologies while exciting had not really been widely adopted because of the difficulties of protein engineering having to make new proteins for every experiment. We realize with Cas9 that the recognition of DNA works fundamentally differently because it requires not a protein DNA interaction, but an RNA-DNA hybridization event, right here. And that meant that you could use the same enzyme for...essentially for any kind of genome editing experiment by simply changing the sequence of the Guide RNA to match a sequence that was at a desired site where you might want to reduce the change in genome. And so that was the idea that we published when we published this work together with the Emmanuelle's lab in the summer of 2012. And so, you know, it's been really exciting over the last five years to watch this technology taking off and of course we, our labs, have been engaged in various aspects of this. And 


\section{CRISPRs: Biology and Technology}

- CRISPRs: RNA-guided genome protection

- Anti-CRISPRs: Phage fight back!

- Ethics: Responsible progress

\section{Many phages encode Cas9 inhibitors}

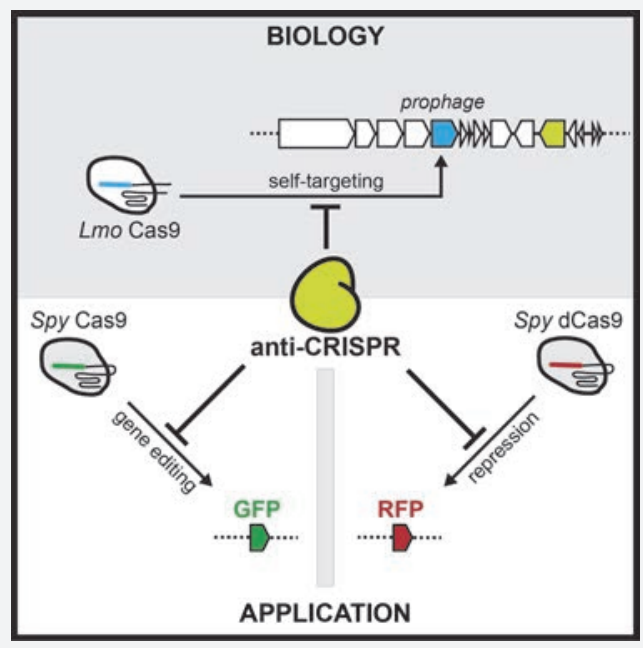

Rauch B et al. and Bondy-Denomy, J. (2017) Cell

\section{Anti-CRISPR blocks Cas9 function}

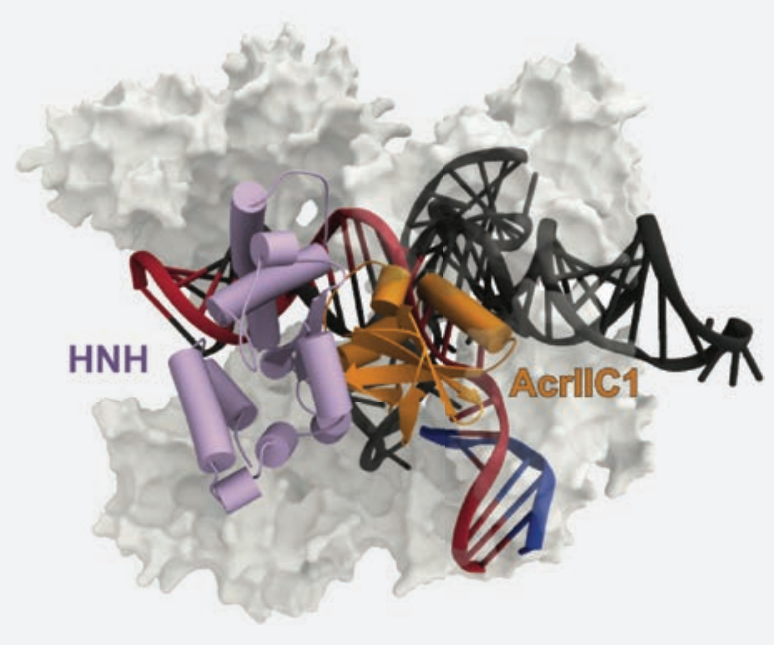

what I thought I would tell you about for the next few minutes and then a little story that I want to tell you about current science we're doing is about our efforts to really understand at a mechanistic level how this works. And why do I care about this? Well, I think it's, first of all, just a fascinating question to think about this mechanism of DNA recognition because you think about it, this is an amazing enzyme that actually has to melt 20 base pairs or maybe a little bit more than that of DNA. And, so DNA has very stably base-paired the two strands, double helix held together, it's very thermodynamically stable, but somehow this enzyme has to melt it open to allow this RNA-DNA hybrid to form. Not only that, it doesn't have any external energy source to do that. So it doesn't hydrolyze ATP which is a classic way that biological enzymes will recruit or sort of transform chemical energy that they can use for other kinds of work. This enzyme doesn't do that and so we wondered how this kind of melting works, and furthermore what that mechanism could tell us about the way this works in... in actual cells and how we might think about using it for other kinds of technical or technological applications.

So, one of the things that's emerged over the last few years is that there's actually a very interesting structural change that happens in this protein as it assembles with nucleic acid. And this is an animation that was made by a first year graduate student, Ben Lafrance, based on research that was done by a former student in my lab, Sam Sternberg. And what this shows you is the protein. Here's a crystal structure of the protein alone, morphing to the structure bound to a Guide RNA, the molecule in orange. And you notice there was a big structural change in this part of the enzyme that allowed it to bind to the RNA and it also opens up a channel in the protein where this guide part of the RNA is actually located. Then when this assembles with DNA, there's an additional structural change that accommodates the RNA-DNA hybrid that forms. And that seemed very interesting and potentially related to this unwinding mechanism, but we also found that there has to be an additional structural change here, in this part of the enzyme, a domain in the protein called $\mathrm{HNH}$ that swings it into place. So it can actually cleave the targeted strand of the DNA. The strand that's actually base-paired with the RNA. And that structural change was not seen in the early crystal structures that were done by various labs because people were using a single strand of DNA to form this hybrid, but without having an actual doublestranded DNA substrate, which is the natural substrate for this enzyme. And so, once it was possible to crystallize, sort of trap that double-stranded form of the DNA on the Cas9 enzyme. Again, here's the orange Guide RNA sticking out, here is the blue and magenta DNA 


\section{An inactive but DNA-bound Cas9}

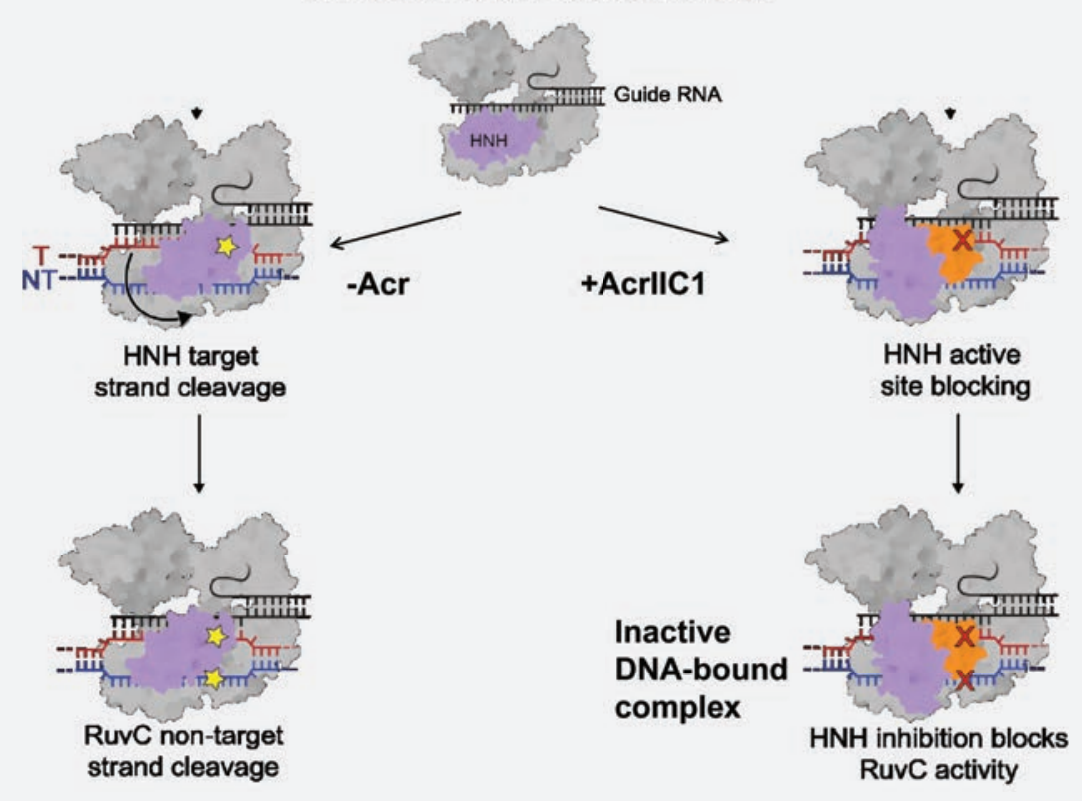

double helix entering the protein and then getting unwound inside the enzyme. We found that in this structure, this HNH cataIytic domain is now actually very close to where it needs to be to cut the DNA. And there are lots of reasons for that, that have to do with the way this protein nucleic acid interaction occurs in the center part of this enzyme. So, it's clearly a very interesting little machine that's set up to interact with nucleic acid and really recognize only the Guide RNA that's meant to bind to and then to interact with DNA molecules to trigger only once it's engaged on a DNA that is based-pairing to the Guide RNA. The adoption of this active structure of the enzyme that's now catalytically competent to cut the DNA.

And so, one of the things that we've been studying is this work was initially based on just modeling of what we knew sort of had to happen in the protein. It was very satisfying to see that structural rearrangement once we had crystallized a trapped structure of Cas9 on a double-stranded DNA substrate, but we really thought it would be interesting to look at the dynamics of this and figure out what affects the formation of that active state of the enzyme. And I'm just going to very briefly tell you about some experiments that were done by several students, Sam Sternberg, Fuguo Jiang, David Taylor and then more recently by Yavuz Dagdas and Janice Chen together with a colleague at Berkeley Ahmet Yildiz. And so what we've been doing with Ahmet's lab is putting pairs of dye molecules into Cas9 in places where we think we can detect this conformational rearrangement of the protein using a method called FRET, which stands for fluorescents resonance energy transfer. You can just detect an actual transfer of energy between these dye molecules, but only when they're close enough to interact. And so, by doing this using a single molecule system, we can actually tether Cas 9 with its Guide RNA onto the surface of a slide and then flow in DNA molecules, and we can control what sequence of DNA we're using here either using a perfect match to the Guide RNA or including... or using DNA molecules that have mismatches to the Guide RNA. And then, we can ask how those affect the rearrangement of the protein structure by monitoring changes in these FRET interactions between pairs of dyes. So, l'm just going to show you one slide that shows what some of these data look like and what we were able to figure out using this method. 


\section{Bypassing Negative Epistasis on Yield in Tomato Imposed by a Domestication Gene}

Graphical Abstract

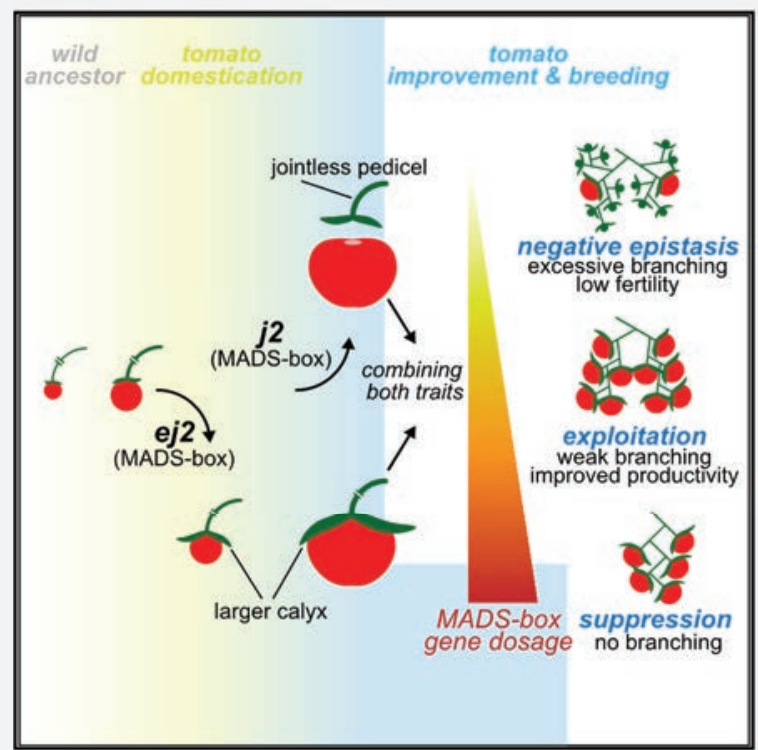

Authors

Sebastian Soyk, Zachary H. Lemmon, Matan Oved, ..., Dani Zamir, Yuval Eshed, Zachary B. Lippman

Correspondence

lippman@cshl.edu

In Brief

Why did a crop domestication gene hinder breeding with a modern breeding gene responsible for the beneficial "jointless" trait in tomato, and how can this genetic interaction be overcome and exploited?

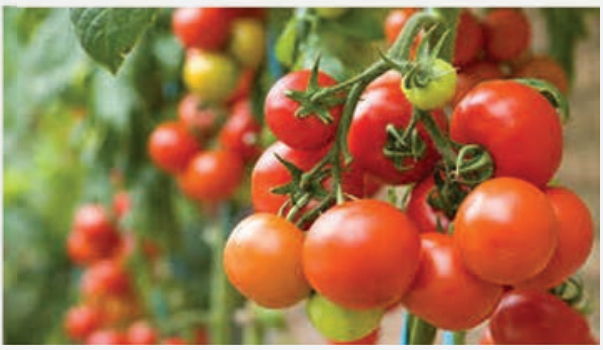

Molecular Therapy

In Vivo Excision of HIV-1 Provirus by saCas9 and Multiplex Single-Guide RNAs in Animal Models

\section{May 2017}

Yin et al. use multiplex CRISPR/Cas9 genome editing technology to excise the HIV-1 provirus in a precise manner in three different HIV-1 animal models via in vivo AAV gene delivery. The feasibility of HIV excision in infected cells in vivo paves the way toward human clinical trials to cure HIV-1 infection.
And so, what I'm showing you here, so again this is the way the experiment is set up. So, we have the Cas9, protein with its Guide RNA that's tethered to a slide and we're flowing in different DNA substrate molecules. And then, we're just monitoring the change in fluorescents resonance energy transfer that happens as a function of different kinds of DNA substrates. And what you can see here is that when we use a fully matched DNA substrate, we get most of the molecules occupying a confirmation that we can monitor shown on this FRET scale right here that indicates a fully active Cas9, a Cas9 that can cut the DNA. We can test that and show that that's true biochemically. But what's very interesting is that, as you introduce even one base 
What about human germline editing?

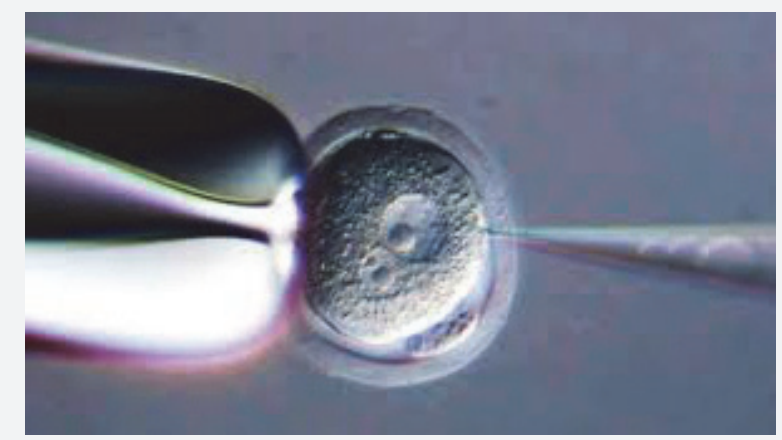

pair mismatch between the DNA and this 20 nucleotide Guide RNA, you start to see population of a state right here, shown in green, that is we found out as we compared these in intermediate state. And then over here on the far right-hand side in blue is a state that is fully inactive. So this is the RNA only confirmation of Cas9 over here before it binds to DNA. It's in that fully inactive state. And so, what was really intriguing was that with different numbers of mismatches between the DNA and its Guide RNA, you can observe that many of the molecules get trapped in this intermediate state and that turns out to correspond to this rotation of that HNH domain, the cutting domain, swinging into place to cut the DNA. So, it really only swings into place efficiently when the system is engaged on a fully-matched target sequence. And that's just sort of summarized. Here, where we identified this, what we call a conformational checkpoint that allows the system to basically allows this protein to ask, am I on a fully matched DNA or DNA that should be, maybe it's a virus and I should cut it, or am I engaged on a mismatched sequence in which case I probably don't — this probably shouldn't be cut and that traps it more of the time in this conformational intermediate state that is not active to cut DNA and can more often just associate. That's one of the mechanisms this system uses to ensure accuracy of DNA recognition and cutting.

So, it turns out that in nature, you might imagine that you know as the systems are sort of evolving and they are evolving in an environment where there's lots of phage, and so phage are constantly adapting and figuring out ways to get around the CRISPR system that you might find ways that phage fight back. And in fact, very recently, just so in the last year, Alan Davidson's lab at the University of Toronto and now more recently Joe Bondy-Denomy at UCSF have actually figured out that there are proteins that phage make that are called anti-CRISPRs. And this is just one example of these and these were found in a very clever way. And so, work that was done originally by April Pawluk when she was a graduate student in Alan Davidson's lab, what they figured out was that if you looked in bacterial genomes that have incorporated an entire phage sequence that we call a prophage to survive and avoid getting cut by the CRISPR system. If it's acquired a sequence that can recognize a sequence in the prophage, the phage has to encode an anti-CRISPR protein that shuts down the CRISPR system. And that's exactly what happens. And so, April, I have to give her a lot of credit. This was really her idea as a graduate student was to go out looking for these and she actually found examples and now many people are digging up lots more examples and we now know these are very, very abundant in nature. And this is just showing an example where you have a selftargeting sequence in the CRISPR array that gets made into a CRISPR RNA that would cut this prophage in the bacterial chromosome and kill the bacterium, except that this prophage encodes a protein that is an anti-CRISPR able to shut down the activity of this enzyme and avoid getting cleaved. So, as a biochemistry lab we thought, we'd love to figure out how this actually work.

And so, I want to just again largely for the students here, I just want to show you a few experiments. I hope you'll indulge me and just share with you kind of how I like to do research in my lab working with my students and how we try to do the research as questions and answers, where we ask a question and then we figure out an experiment that we can do to answer the question hopefully. Lots of times we don't answer it, but sometimes we get lucky and we do. And then that often leads to the next question, and then it sort of goes on. And so the first question we asked was, you know, if we compare different examples of these anti-CRISPR proteins, and 
Acknowledgments

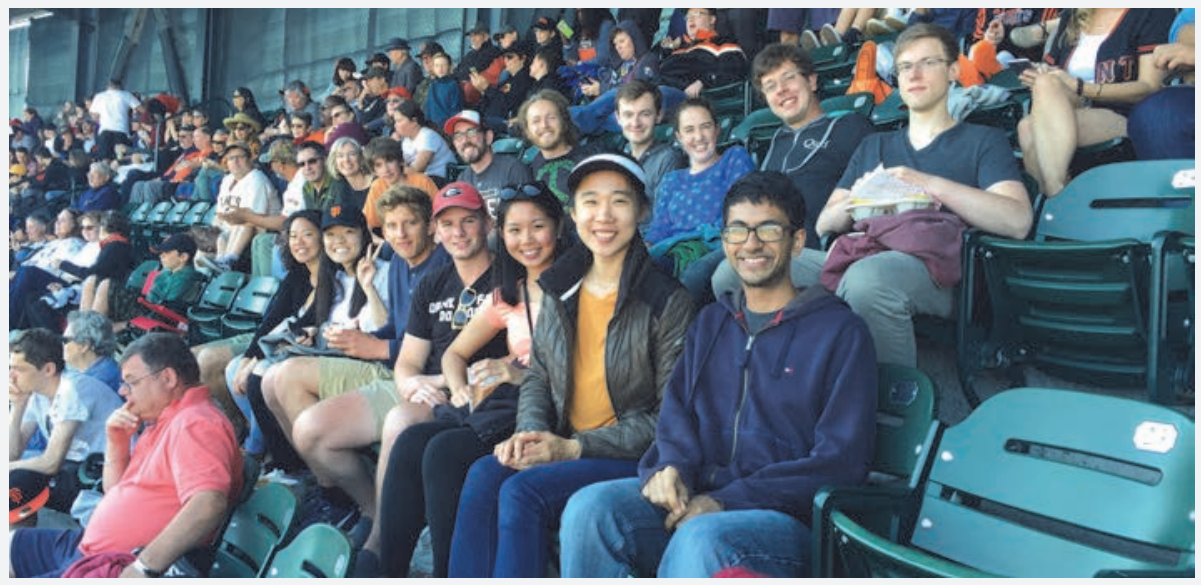

Kryz Chylinski

Emmanuelle Charpentier - MPI Berlin

Yavuz Dagdas, Ahmet Yildiz - UC Berkeley

Karen Maxwell, Alan Jacobson - Univ. of Toronto Erik Sontheimer - U. Mass Medical Center Joe Bondy-Denomy - UCSF
THE

PAUL G. ALLEN FRONTIERS GROUP

C R $\longdiv { B }$ 1010 | $\begin{aligned} & \text { Howard Hughes } \\ & \text { Medical Institute }\end{aligned}$

of Cas9 enzymes. So, this is showing a phylogeny of these proteins. So, if we look at the relationships of different bacteria, sort of illustrated by this phylogenetic tree, and many of these have Cas9 enzymes. And, if you look at the relationship of these Cas9 proteins to each other, they can be really very divergent. There is a few conserve features, but a lot of them are quite distinct from each other. And so, this is an experiment that was done by Lucas Harrington

by the way, these are all very small proteins that are typically less than a 100 amino acids inside, so they're very small. And we started working with Alan Davidson and Karen Maxwell at University of Toronto and a few of the ones at their lab had identified. And, what we found out was that there were some really striking differences in the way these different anti-CRISPR proteins actually function. And that led to the finding that we found one that was sort of unusual in a sense because it really turns out to be a broad spectrum inhibitor

\section{Company connections}

$\begin{array}{ll}\text { Co-founder: } & \text { Caribou Biosciences } \\ & \text { Editas Medicine } \\ & \text { Intellia Therapeutics }\end{array}$

SAB member: $\quad$ Caribou Biosciences Intellia Therapeutics eFFECTOR Therapeutics Driver

Scientific Pfizer, Inc. collaborations: Roche Biopharma and Kevin Doxzen, two graduate students in the lab, where they're able to take purified anti-CRISPR proteins that are called $\mathrm{C} 1, \mathrm{C} 2$, and $\mathrm{C} 3$ and add them to biochemical reactions that we were conducting using purified Cas 9 enzymes. And in this experiment, we're actually using four different purified Cas9 proteins that come from different parts of this phylogenetic tree. And what we found, so the way this experiment works is that we take, this is a DNA molecule and we're separating it by size on a gel system here. So, here's un-cleaved DNA, if we add the Cas9 enzyme with an appropriate Guide RNA, we get DNA cutting. And you can see that for all four of these Cas9 proteins. And then here's the cool thing. So, this anti-CRISPR protein called $\mathrm{C} 1$ is a robust inhibitor of all three of these Cas9 proteins, not of this one here at the strep pyogenes Cas9 because it's quite distantly related from these. But these are also proteins that are really quite divergent from each other. And just to show you that that's really an unusual property, these two anti-CRISPR proteins here only inhibit one type of Cas9, this one here and not these others. So that we thought that, that seemed very intriguing and work that was done in our lab and also by Erik Sontheimer's lab showed that you could use these anti-CRISPR proteins in cell-based experiments to inhibit genome editing that was triggered by Cas 9 and see the same thing that the $\mathrm{C} 1$ protein was a diverse inhibitor of Cas 9 homologs whereas the C3 protein could only shut down a single Cas9. 


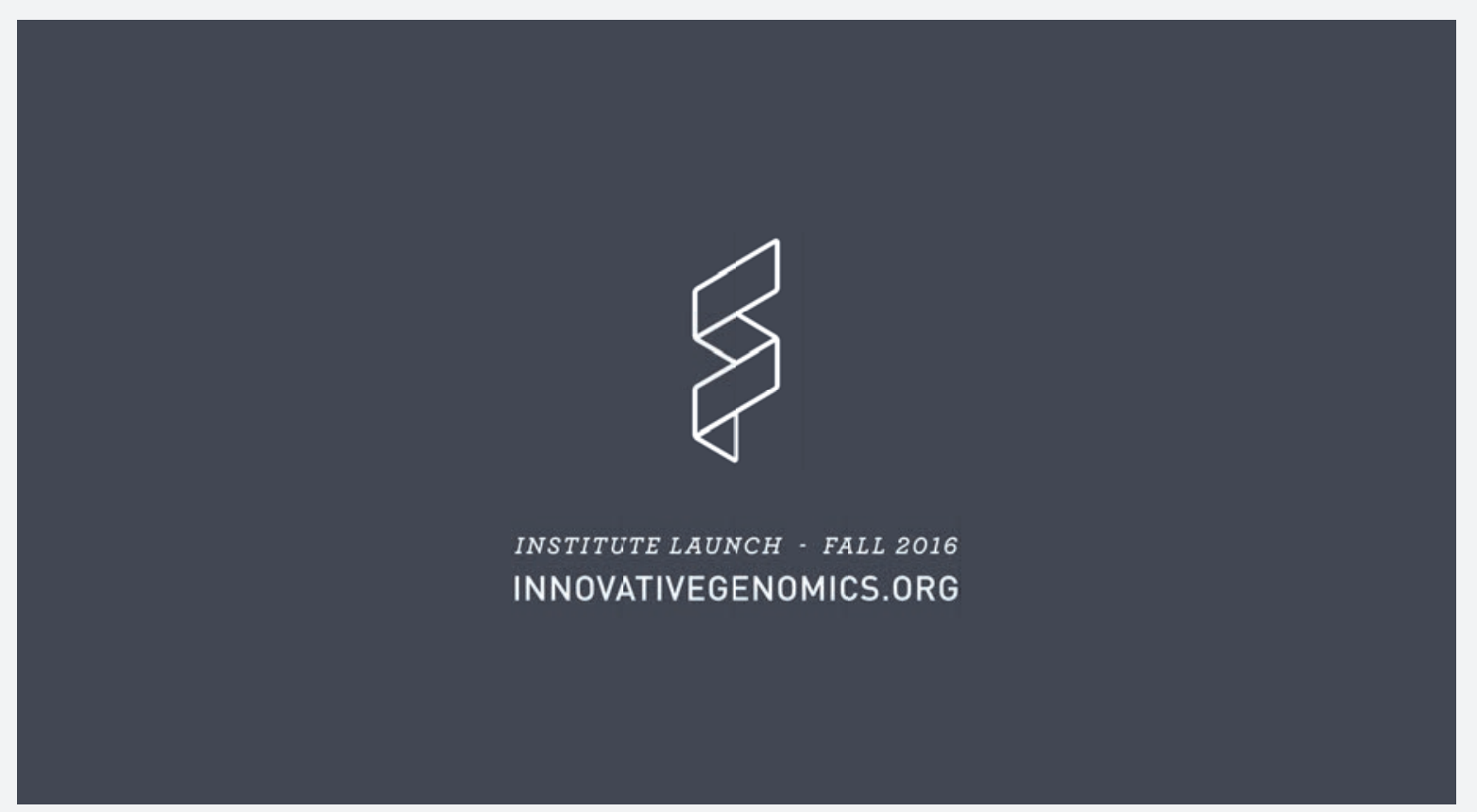

And so, then the question was, how is this working? And so, as biochemist, we could ask well, you know, at what step of the reaction that's catalyzed by Cas 9 would this inhibitor be blocking? And so, one of the things that was interesting, so this is a little cartoon of Cas9 with its Guide RNA here in black at the top and here is the target strand and the non-target strand of the DNA at the bottom with the two active sites of the enzyme making a cut. And so, these students, Lucas and Kevin, did a biochemical experiment to ask, first of all, does this inhibitor block DNA cutting? And the answer was, it does. And so again, this is looking at - these are we're looking at DNA molecules and their change in size when they get cleaved by Cas9. So, if we just have Cas9 alone, we get lots of cutting, two different enzymes being used here and here. If we use the inhibitor, at the inhibitor you can see that now we're not getting cutting. This experiment was done in a special way. We were able to label either strand of the DNA so we could figure out, is this strand getting cut or is this strand getting cut. And you might or might not be able to see it, but we saw that. For the most part, DNA cutting was turned off except there was a trace of cutting right here for this strand of the DNA. And that made us think that there might be something interesting going on, that maybe the reason that the DNA wasn't getting cut was... had to do with the chemistry of the reaction because you could say, well maybe it doesn't cut the DNA because it just doesn't bind to the DNA. And so, the test whether it binds to the DNA, these students did an experiment in which they took this Cas9, Guide RNA, DNA complex and added this $\mathrm{C} 1$ inhibitor to it. And then they asked to figure out whether the DNA stays bound to the protein. They simply looked at its migration in this kind of a gel system where we can separate molecules by size or even big complexes of molecules. And what we found was that when we have the protein alone, we get DNA cutting, which I showed you before, but once we have this inhibitor, now there's a very large sized collection of sort of conglomeration of molecules, a complex of molecules, that is trapped and we can see that by its slow migration in this gel system. So, this really said that what this anti-CRISPR protein does is to trap Cas9 in an inactive but DNA bound state.

So, how do we, you know, figure out where it's binding? And so, the students were able to make a series of truncated forms of the protein and ask which ones of these truncated proteins are able to bind to this anti-CRISPR. And this is just sort of summarizing the result here, and if you were to compare this in detail what you would see is that the common feature of protein truncations that could bind to the $\mathrm{C} 1$ antiCRISPR was the presence of this HNH catalytic domain that suggested that this domain might be directly binding to the $\mathrm{C} 1$ protein, something that we could show by separating the $\mathrm{C} 1$ complex bound to the HNH domain. This is actually a chromatography column where we separate things by size. And, we found that only when we have this HNH domain of the Cas9 protein plus the $\mathrm{C} 1$ anti-CRISPR, we got migration of a bigger, larger sized interacting complex right here. And students went on, they were able to solve a crystal graphic structure of this and they found out that this anti-CRISPR actually binds to the active site of the HNH domain. So, it's literally blocking the site 
that in this protein that's necessary for chemistry, necessary to cut this one strand of the DNA. And furthermore, this really explains why it's a broad spectrum inhibitor of Cas 9 because this is one of the most conserved parts of these enzymes. Lots of other parts of the protein can change, but the fundamental chemical reaction that these are catalyzing stays the same and it's been maintained over evolutionary time. So isn't it interesting? I thought it was fascinating that this anti-CRISPR protein has figured out how to interact with that site. And furthermore, we think it actually blocks the rotation of this $\mathrm{HNH}$ domain into position to cut the DNA. So, it's really an inhibitor that takes advantage of this conformational flexibility of Cas 9 that we had determined from these biochemical experiments. And this is just summarizing this and we were curious about whether this inactive DNA bound complex might actually be used in bacteria to harness Cas9, not for DNA cutting but maybe for DNA regulation because it actually traps this protein on DNA at sites that are dictated by the Guide RNA. It's something that we're studying now.

And so, just about done, I just want to mention a couple of things about ethics. And, so in thinking about the way that genome editing is being deployed now around the world for technologies that span agriculture, human health, and various kinds of research, one of the things that's become clear is that, things are...the pace of this research is incredibly fast. And, I just wanted to show you two, especially for the students, two recent examples. So this is a paper that just came out recently where a team at Cold Spring Harbor Lab was able to use the Cas9 system to alter genes in tomatoes that make them less prone to branching and breaking off of these branches of fruit. Something that would have been really hard, maybe impossible, to do by classical breeding methods, but now can be done using precision gene editing. And then also, paper that got a lot of attention recently was a team in China that used Cas9 to remove integrated HIV sequences, the virus that causes AIDS from genomes of mice using a very efficient way of delivering Cas9. And, so these are applications, like this example is an application that would apply to an adult animal or if you were doing it in a patient, an adult patient, but there's been also a lot of talk about germline editing, meaning being able to inject editing molecules into fertilized eggs or embryos that would lead to heritable changes to DNA. And people have been doing this from very early days with gene editing systems including Cas9 in animals, but this can also be done in principle in humans. It's certainly been done in primates and that has led to my involvement in a really interesting series of meetings and discussions around this topic and how we encourage responsible use of this technology moving forward.

And, I just want to point out that the National Academies of Sciences and Medicine in the US recently put out this report on human genome editing that really encouraged research using this kind of technology, even in embryos, but suggested a worldwide pause or one might say moratorium on use clinically in humans until it can thoroughly be evaluated as a technology, and certainly from an ethical perspective as well.

So, I think for the students, this kind of just illustrates some of the challenges that happen when you're doing research in your lab. It leads to technology that is going in directions that one couldn't have predicted initially and where, I think it's at that point really important for scientists, all of us, to engage in the conversation about responsible progress. And l'd just like to close by acknowledging a fantastic group of people. This is a picture of folks in my laboratory. We've had, of course, incredible collaborators over the years, Emmanuelle and Christoph and then I mentioned these folks as well and then our funding over here. And thank you for your attention. 